\title{
DISCUSSÃO SOBRE A EFETIVIDADE DO MONITORAMENTO AMBIENTAL NO IMPACTO CAUSADO POR RESÍDUOS SÓLIDOS DA CONSTRUÇÃO EM MANANCIAIS E PROPOSTAS DE UM PLANO DE GESTÃO.
}

Luiz Felipe Abreu Cavalcanti - luizfelipecavalcanti22@gmail.com Fundação Mineira de Educação e Cultura (Universidade FUMEC) Rodrigo de Oliveira Carvalho - rodrigoc.engenharia@ gmail.com Fundação Mineira de Educação e Cultura (Universidade FUMEC) Juliana da Silva e Mascarenhas Guedes - jsguedes@ fumec.br Fundação Mineira de Educação e Cultura (Universidade FUMEC) 


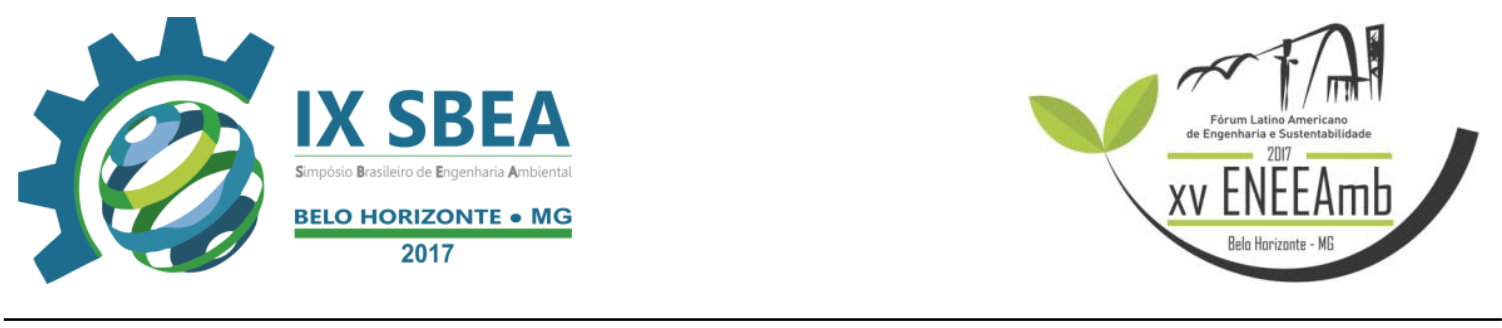

\section{RESUMO}

Este trabalho apresenta a viabilidade preliminar de uma ferramenta de fiscalização da cadeia de produção dos resíduos sólidos da construção, desde sua origem até o seu descarte, uma vez que foi constatada a falta de eficiência e vulnerabilidade do atual sistema de monitoramento ambiental. O PGR Global, como foi denominado o método que proposto, nessa pesquisa, após análises dos impactos da incorreta deposição de resíduos sólidos nos recursos hídricos. Foi constatado que os mananciais estão vulneráveis a assoreamento, contaminação e eutrofização, e que estes fenômenos inviabilizam a água para consumo humano, e prejudicam o equilíbrio do ecossistema local. A partir disto, o PGR Global foi criado como um plano de gestão integrada entre engenheiros civil e ambiental, com parceria entre o setor público e privado, a fim de promover um maior monitoramento ambiental sobre a destinação do resíduo produzido, e tornar as construções ecologicamente sustentáveis.

Palavras-chave: Resíduos sólidos, construção civil, integração, PGR (Plano de Gestão de Resíduos)

\section{INTRODUÇÃO/OBJETIVO}

O mundo está cada vez mais urbanizado, e o crescimento de sua população é diretamente proporcional a demanda de infraestrutura de transporte, moradia e saneamento nas grandes cidades (IBGE, 2001). Desta forma, um dos problemas enfrentados pela sociedade no século 21 , consiste no balanceamento da geração excessiva de resíduos sólidos de origem doméstica, industrial, e principalmente provenientes da construção civil, objetivo deste estudo, com a sua correta destinação no meio ambiente.

Baseado no fato de que as cidades não podem parar de crescer e de prover estrutura para seus moradores, propõe-se a introdução de um modelo de monitoramento ambiental, que controle e regulamente a produção e destinação dos resíduos sólidos, visto que sua despensa incorreta pode acarretar, dentre outros, a contaminação dos recursos hídricos. 


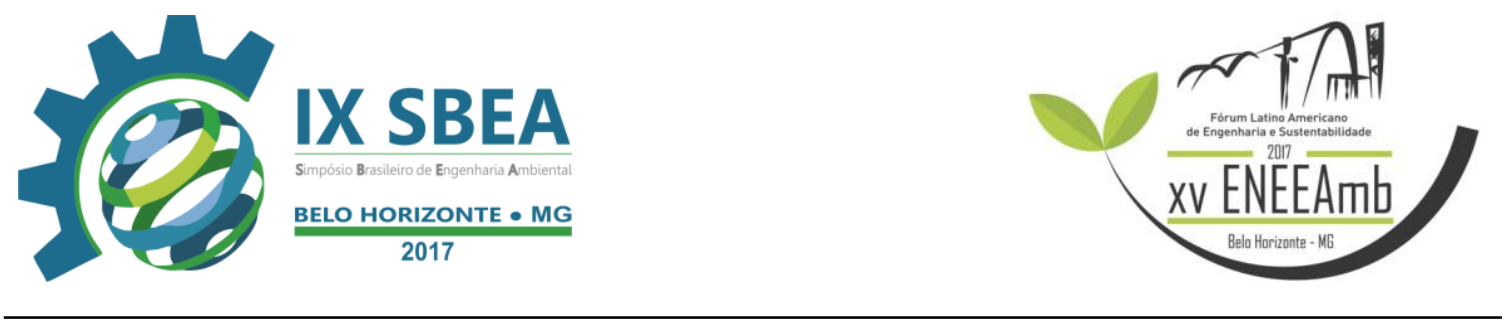

Através de análises e discussões sobre o impacto provocado pela incorreta destinação deste volume de RCD (resíduos sólidos da construção e demolição) nos mananciais, este artigo pontuou e exemplificou problemas recorrentes causados por essa ação desordenada, como o assoreamento, a contaminação do lençol freático, e a inviabilização da água como consequência da eutrofização.

\section{METODOLOGIA}

A metodologia utilizada para a elaboração de um sistema de monitoramento ambiental integrado, denominado de PGR Global, foi baseada na percepção da necessidade de haver uma maior fiscalização na relação: crescimento da construção civil e balanceamento de resíduos sólidos. O plano de gestão integrado considera diversos aspectos práticos e físicos, importantes para o desenvolvimento e construção sustentável, de forma a agrupar e promover o levantamento prévio da geração de resíduos da edificação, controle e gerenciamento durante a execução.

O PGR Global deverá obrigatoriamente obter fatores como:

- Levantamento prévio de volume de resíduo sólido, a ser analisado na fase de anteprojeto;

- Plano de descarte para sólidos não reaproveitáveis;

- Plano de reaproveitamento dos resíduos gerados;

- Assinatura de Engenheiros Civil e Ambiental atestando a veracidade dos dados.

Durante o estágio de aprovação do projeto perante ao órgão público municipal, os proprietários e desenvolvedores dos empreendimentos deverão efetuar o cadastro da unidade juntamente com seu PGR Global. Uma vez o plano de gestão de resíduos protocolado, será responsabilidade do órgão público municipal fiscalizar e acompanhar a produção, descarte e reaproveitamento dos resíduos destas edificações, fazendo valer o plano previamente apresentado.

De acordo com Klunder (2005), a gestão integrada e sustentável dos resíduos sólidos (ISWM) inclui a redução da produção nas fontes geradoras, o reaproveitamento, a coleta seletiva com inclusão de catadores de materiais recicláveis e a reciclagem, e ainda a recuperação de energia. 


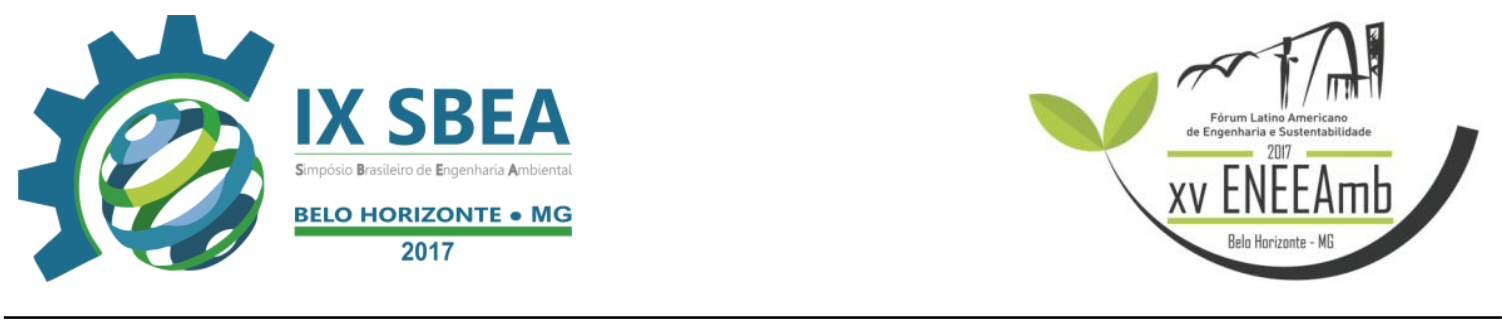

A fiscalização e autorização da implementação do PGR Global se dá por meio de um órgão público municipal, composto por agentes devidamente qualificados e adequados para esse modelo de gestão. Setor o qual é responsável por uma análise minuciosa do levantamento prévio apresentado, objetivo, descarte e reaproveitamento dos resíduos, tal como sua veracidade. Todo o processo deverá passar por inspeções periódicas, de forma não comunicada, promovidas pelo órgão público municipal.

Ao final da execução em conformidade com o PGR Global apresentado, é disponibilizado ao proprietário um selo próprio da metodologia, o qual certifica a construção em forma sustentável a agregar ainda mais valor, monetário ou não, à edificação ao representar a responsabilidade social e ambiental do empreendimento perante a sociedade.

\section{RESULTADOS E DISCUSSÃO}

\section{$\underline{4.1 \text { A incorreta destinação e o assoreamento de mananciais }}$}

Os resíduos sólidos de uma forma geral, possuem inúmeras variedades, classificações e diferentes origens (JACOBI, 2011). Desta forma, cada tipo de resíduo sólido, independente de sua origem, requer um tratamento específico e esse é um dos desafios dos responsáveis por está destinação. Segundo Takenaka (2008), a crescente tendência de crescimento e concentração da população em grandes centros, cria uma enorme demanda por infraestrutura habitacional, industrial e de transporte para atender os moradores. Este crescimento urbano, quando não é devidamente planejado, agrava uma das principais consequências das atividades humanas, que consiste justamente na geração de resíduos.

Dentre os vários tipos de resíduos consequentes do crescimento urbano, aquele proveniente da construção civil é o que possui um dos menores controles de destinação, e monitoramento ambiental. De acordo com o Ministério do Meio Ambiente (2011), a média de produção de resíduos da construção no Brasil era de 99.354 t/dia, e que apenas $52,79 \%$ dos municípios brasileiros exerciam o controle sobre terceiros para destinação deste resíduo sólido. 


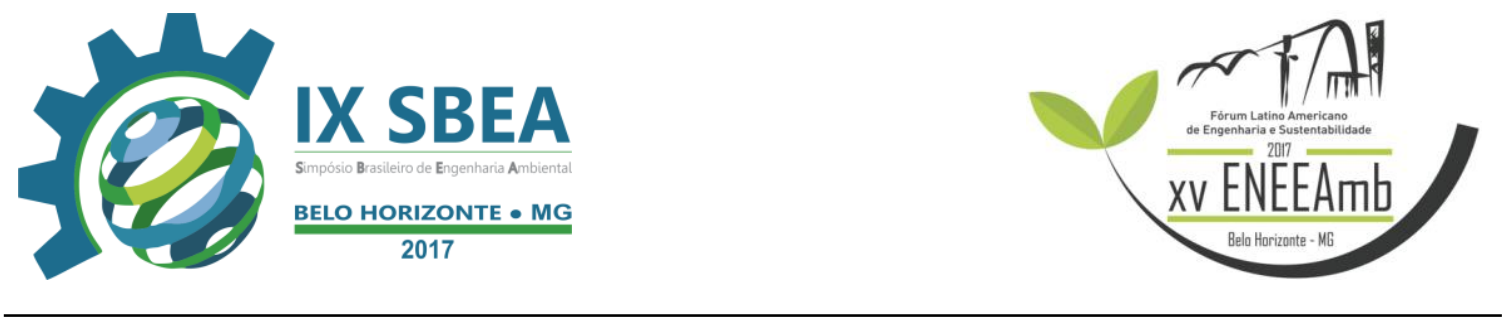

Diariamente, grandes e pequenas quantidades de resíduos são produzidos nos municípios, e sua destinação nem sempre é apropriada, visto que inexistindo um monitoramento eficaz, e uma devida instrução oriunda dos órgãos públicos sobre a correto despejo, este volume sólido acabará em áreas desocupadas, normalmente, em zonas da região metropolitana, denominadas de bota-fora. Segundo De Paula (1999), estes bota-foras podem ser áreas de pequeno ou grande porte, privadas ou públicas, que são designadas de forma oficial ou não oficial para recepção dos resíduos sólidos da construção. Portanto, devido ao ritmo acelerado de deposição e produção de resíduos, os bota-foras legalizados são saturados rapidamente. Consequentemente, as empresas responsáveis pelo transporte e destinação do rejeito da construção civil, a fím de economizar recursos ao evitar áreas de descarte privadas, optam por destinar este volume em locais próximos a mananciais, em regiões periféricas as quais não há fiscalização e monitoramento do poder púbico, por conseguinte, a causar o assoreamento dos afluentes.

De acordo com Tucci (2007), as mudanças no estilo de ocupação das bacias hidrográficas, de uma forma geral, implicam na ocupação do meio urbano em áreas ambientais. Desta forma podem impactar diretamente o ciclo hidrológico da bacia. Dentre estes, o assoreamento dos mananciais é consequência grave desta ocupação desordenada, uma vez que grande parte dos resíduos sólidos advindos da construção ou demolição acabam depositados nos leitos dos rios, como mostra a Figura 01.

Figura 01: Obstrução de Curso Dágua - Córrego Camarões

Fonte: Câmara Municipal de Belo Horizonte, 2017

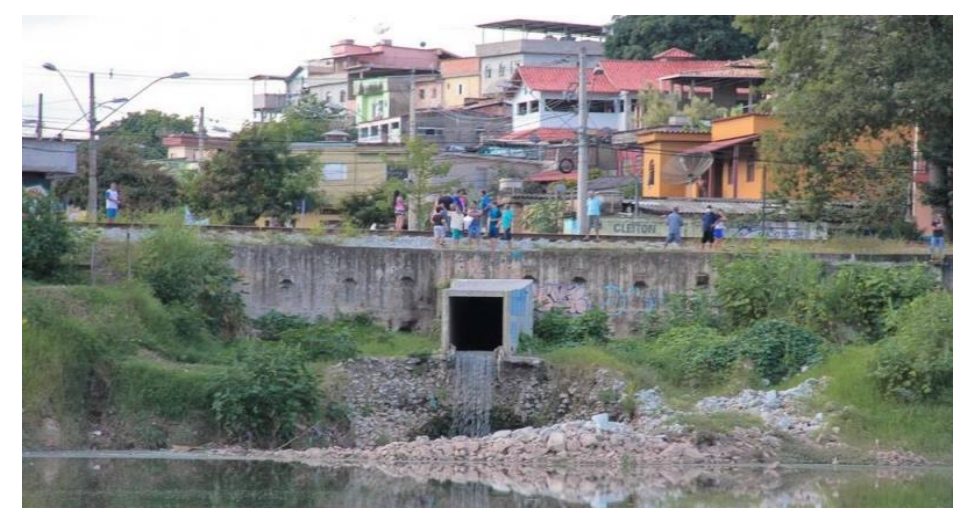




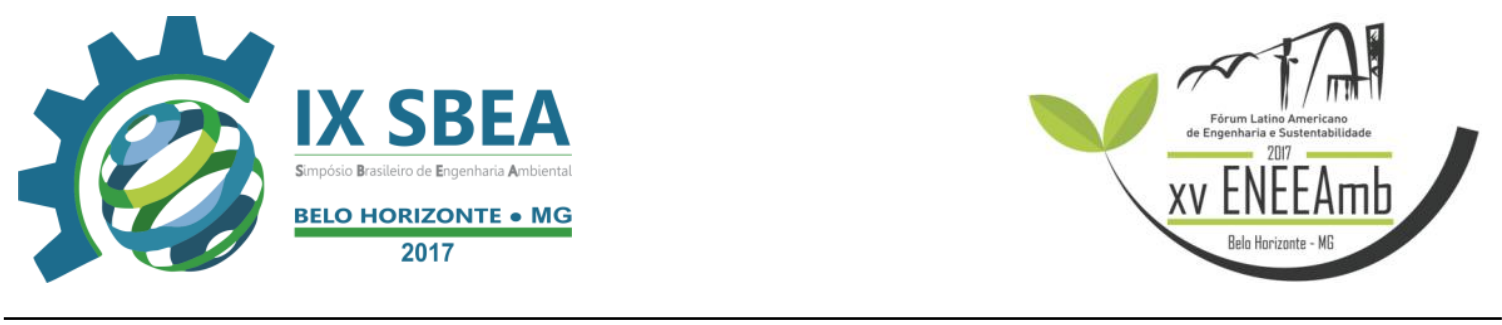

Em linhas gerais, os cursos d'água que circundam os grandes centros urbanos servem como fontes de captação de água potável para a população. A grande questão, entretanto, se baseia no fato de que está água vem sendo inviabilizada para o consumo humano. Isto porque as características físicas naturais dos mananciais, como sua profundidade, e principalmente, sua vazão, vem sendo afetada pelo assoreamento (JULIEN,1998). O processo de sedimentação acarreta na redução da capacidade do rio de ceder água, já que não há volume útil para ser captado, e os equipamentos outrora utilizados para o processo, não são mais eficientes. Além disso, em alguns casos mais graves, ocorre a inviabilização da água para consumo, como consequência da natureza dos resíduos despejados no manancial, e do nível de partículas sólidas em suspensão. Item que será abordado nos próximos tópicos.

\subsection{Os resíduos sólidos da construção classe C e D, e a contaminação do lençol} freático

De acordo com a Associação Brasileira de Águas Subterrâneas, lençol freático pode ser definido como um reservatório de água abaixo do nível do terreno, que se acumula no espaço entre fraturas de rocha. Por se tratar do provedor de água potável para os rios e córregos da superfície, é imprescindível para a qualidade dos mananciais que o lençol freático seja isento de contaminação advinda de resíduos que, quando indevidamente depositados no solo, reagem com a água presente no mesmo, e por gravidade, acabam se depositando nestes reservatórios subterrâneos.

Segundo o Programa Ciência Viva, cerca de $22 \%$ do total de água doce do planeta está em forma de água de subterrânea, localizada no lençol freático e aquíferos. Dentre os vários potenciais contaminantes do lençol freático, como fertilizantes e pesticidas agrícolas, vale destacar a contaminação devido a destinação incorreta de resíduos da construção civil.

Baseado na Resolução 307 do Conselho Nacional do Meio Ambiente - Conama (2002), os resíduos de construção civil podem ser definidos como: "os provenientes de construções, reformas, reparos e demolições de obras de construção civil, e os resultantes da preparação e da escavação de terrenos, tais como: tijolos, blocos 


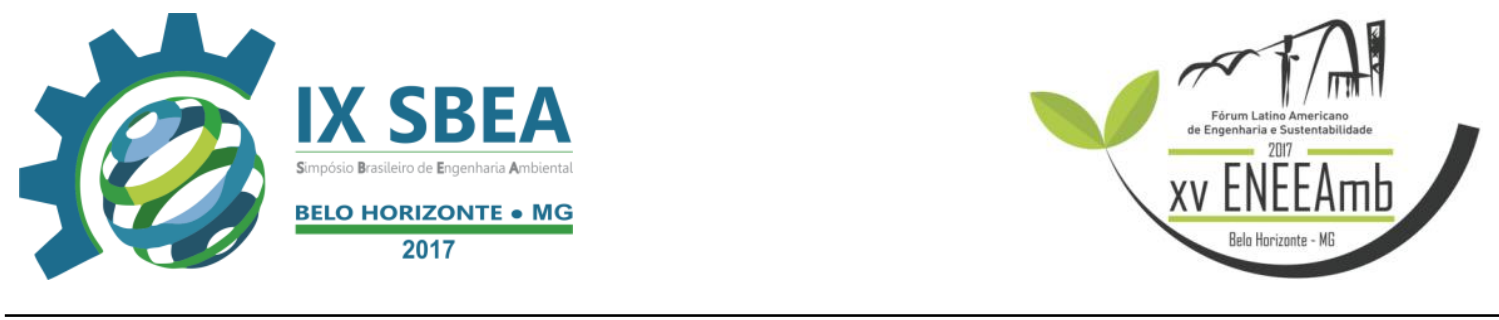

cerâmicos, concreto em geral, solos, rochas, metais, resinas, colas, tintas, madeiras e compensados, forros, argamassa, gesso, telhas, pavimento asfáltico, vidros, plásticos, tubulações, fiação elétrica etc., comumente chamados de entulhos de obras, caliças ou metralha (CONAMA, 2002)."

Portanto, a variedade de materiais depositados de forma irregular, com diferentes propriedades e composições químicas, acarretam em diferentes tipos de contaminação do solo, e consequentemente, dos recursos hídricos presentes na região. A destinação destes resíduos, em sua maioria, é feita de forma clandestina, em locais como terrenos baldios, margens de mananciais e ruas de periferias, resultando problemas ambientais e sociais, como a contaminação do solo por gesso, tintas e solventes, e o agravamento de problemas de saúde pública. (MENDES,2004).

Quadro 01: Classificação dos resíduos conforme Conama n 307 e n 431

\begin{tabular}{|c|c|c|}
\hline CLASSE & DEFINIÇÃO & EXEMPLOS \\
\hline A & $\begin{array}{c}\text { Resíduos reutilizáveis ou recicláveis com } \\
\text { agregados }\end{array}$ & $\begin{array}{c}\text { Componentes cerâmicos, argamassa, } \\
\text { concretos, solos, etc. }\end{array}$ \\
\hline B & $\begin{array}{c}\text { Resíduos recicláveis para outras destinações } \\
\text { C }\end{array}$ & $\begin{array}{c}\text { Plástico, papel, papelão, metais, } \\
\text { vidros, madeiras, outros. } \\
\text { desenvolvidas tecnologias ou aplicações } \\
\text { economicamente viáveis que permitam a sua } \\
\text { reciclagem/recuperação }\end{array}$ \\
\hline D & $\begin{array}{c}\text { Resíduos perigosos ou aqueles contaminados } \\
\text { oriundos de demolições, reformas e reparos } \\
\text { de clínicas, instalações industriais e outros. }\end{array}$ & $\begin{array}{c}\text { Tesso, lixas e mantas asfálticas. } \\
\text { resíduos contaminantes. }\end{array}$ \\
\hline
\end{tabular}

Fonte: Brasil $(2002 ; 2011)$ 


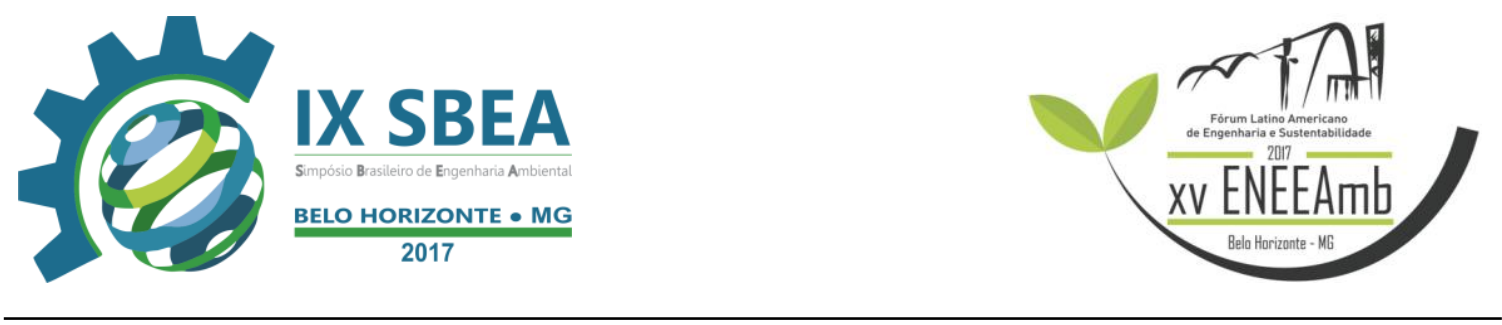

O gesso é produto do aquecimento e posterior moagem de sua matéria prima, a gipsita. Tendo larga aplicação na construção civil como forma de acabamento, o material possui alto índice de desperdício, consequência da grande quantidade de detalhes estéticos no acabamento e necessidade de umidificação para uso, tendo como fim o bota-fora, nem sempre legalizado. A geração, descarte e contato desse resíduo com o solo, gera impacto ecológico, pois este material é tóxico, libera íons $\mathrm{Ca} 2+\mathrm{e}$ SO42, que alteram a alcalinidade do solo (Nascimento, 2010). A alteração da alcalinidade do solo tem como consequência a contaminação do lençol freático. (HARADA, 2009)

\subsection{Inviabilização dos recursos hídricos, e a eutrofização da água}

A eutrofização dos recursos hídricos é consequência do enriquecimento excessivo de suas águas por nutrientes como nitrogênio e fósforo oriundos da contaminação dos afluentes devido ao despejo de esgoto. Estes nutrientes resultam no crescimento exagerado de plantas aquáticas, tanto planctônicas quanto aderidas, com impacto direto no equilíbrio do ecossistema aquático, e progressiva degeneração da qualidade da água dos mananciais (FIGUEIRÊDO, 2007).

Por se tratar de um processo em sua maioria antrópico, ou seja, de origem humana, a eutrofização é uma realidade eminente em grande parte dos grandes centros do Brasil, principalmente aqueles cujo a periferia é circundada de mananciais e cursos d'água (MENEZES,2010). Nestes locais, o crescimento urbano é acelerado (IBGE,2001). Obras públicas e privadas dominam a cidade, e a geração de resíduos sólidos acompanham o ritmo frenético e desordenado de crescimento. Grande parte dos terrenos utilizados para construção desta infraestrutura não apresentam topografia suave, consequentemente, demandam grande movimentação de terra para sua viabilização. As disposições irregulares e os aterros clandestinos, ocasionados pela falta de gerenciamento, tornaram-se uma realidade no território nacional (ANGULO, 2011). Apesar da existência de bota fora legalizado, grande parte dessa massa de terra acaba em terrenos baldios, não controlados, e muitas vezes, estes terrenos podem estar localizados próximos a córregos e rios. Os resíduos que se acumulam em cursos d'água, por diversas vezes, necessitam ser dragados, como mostra a Figura 02 . 


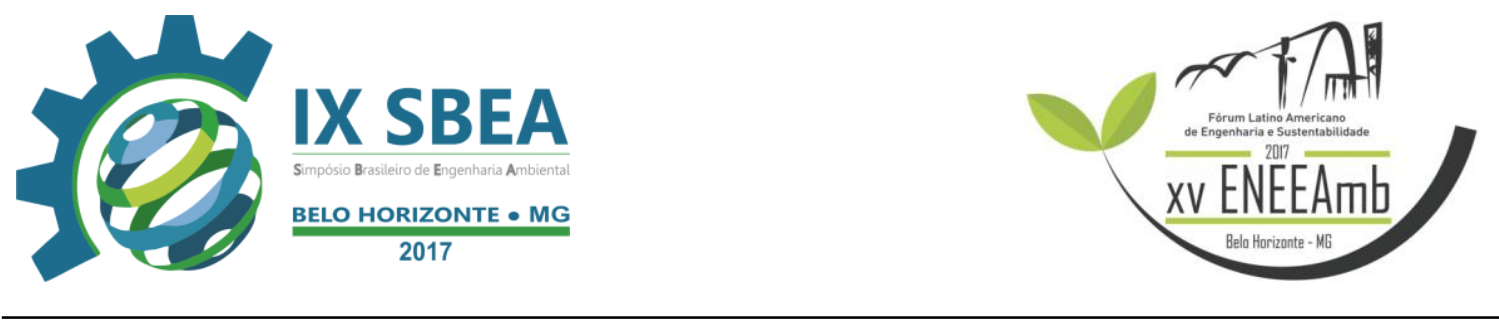

Figura 02: Dragagem de córrego com volume de terra em seu leito

Fonte: Jornal Emtempo, Altemar Alcântara/Semcom

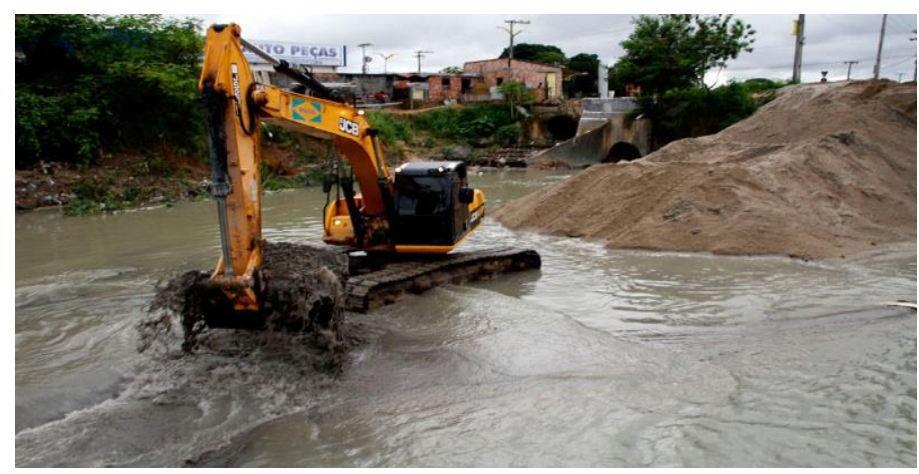

Os resíduos da construção e demolição (RCD) representam, em média, 50\% da massa dos resíduos sólidos urbanos (PINTO, 1999), tanto no Brasil como em outros países, e o material proveniente da regularização e urbanização de terrenos está incluso nesta porcentagem. A deposição deste material rico em matéria orgânica, composto em sua maioria por terra e vegetação, gera a eutrofização dos mananciais. Dentre as inúmeras consequências deste processo degradativo, segundo Esteves (1988) e Tundisi (1986), vale ressaltar que o aumento dos percentuais de nitrogênio e fósforo, eleva a quantidade de plantas aquáticas submersas e flutuantes que podem dificultar a navegação de barcos por meio do entupimento de turbinas, e ainda inviabilizar a água para consumo, pelo fato de alguns tipos de algas serem tóxicas e liberarem toxinas, que podem causar sabor e mal cheiro na água.

\section{CONCLUSÕES/RECOMENDAÇÕES}

O crescimento desordenado das cidades está estritamente ligado a produção exagerada de resíduos sólidos nestes grandes centros, e a falta de eficácia no monitoramento do descarte dessa matéria tem impacto direto na qualidade das águas dos mananciais localizados em torno destas cidades. Desta forma, fenômenos como o assoreamento, a contaminação do lençol freático e a eutrofização de cursos d'água, são consequências diretas dessa ausência de fiscalização no descarte de resíduos. Afim de controlar a produção e balancear o volume de descarte, o PGR Global vem como um modelo preliminar alternativo, para propor uma gestão e fiscalização integrada, que visa preservar os recursos hídricos, e como consequência, agregar valor as empresas e 
produtos, através de um selo de produtor e prestador de serviço responsável. Para estudos posteriores, será analisada a aceitação no mercado da metodologia em questão, e seu impacto e eficiência na melhoria da qualidade dos mananciais.

\section{REFERÊNCIAS BIBLIOGRÁFICAS}

ASSOCIAÇÃO Brasileira de Águas Subterrâneas. Disponível em: <http://www.abas.org/index.php>. Acesso em: 18 de maio de 2017.

ESTEVES, F.A. Fundamentos de limnologia. Rio de Janeiro: Interciência. 1988. 575p.

INSTITUTO Brasileiro de Geografia e Estatística. Disponível em: < http://www.ibge.gov.br/home/presidencia/noticias/11122001onu.shtm >. Acesso em: 29 de maio de 2017.

JACOBI, P.R., BESEN, G.R. Gestão de resíduos sólidos em São Paulo: desafios da sustentabilidade. 2011. Estudos avançados, $\mathrm{n}^{\circ} 25$, pp71.

KLUNDER, A. et al. Concept of ISWM. Gouda: Waste, 2001.

MENDES, T. A., REZENDE, L. R., OLIVEIRA, J. C., GUIMARÃES, R. C., CAMAPUM DE CARVALHO, J., VEIGA, R. Parâmetros de uma Pista Experimental Executada com Entulho Reciclado. Anais da 35a Reunião Anual de Pavimentação, 19 a 21/10/2004, Rio de Janeiro - RJ, Brasil, 2004. 11 p.

MENEZES, P.H.B.J, Avaliação do efeito das ações antrópicas no processo de escoamento superficial e assoreamento na Bacia do Lago Paranoá. 2010 (Dissertação de Mestrado) - Universidade de Brasília, Brasília, 2010.

Ministério do Meio Ambiente. Resolução n. 307, de 5 de julho de 2002, estabelece diretrizes, critérios e procedimentos para a gestão de resíduos da construção civil. 2002. Diário Oficial da União, n. 136, de 17 de julho de 2002, Seção 1, p. 95-96.

Ministério do Meio Ambiente. Resolução n. 431, de 24 de maio de 2011, que altera o artigo $3^{\circ}$ da Resolução $n^{\circ}$ 307. 2011. Diário Oficial da União, n. 96, de 25 de maio de 2011, p. 123. 


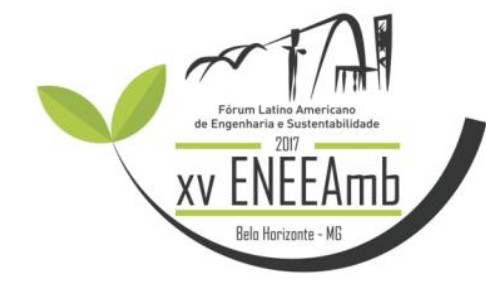

MONTEIRO, J.H.P. et. al. Manual de Gerenciamento Integrado de Resíduos Sólidos-

Rio de Janeiro: IBAM, 2001. 200p.

PINTO, T.P. Metodologia para a gestão diferenciada de resíduos sólidos da construção urbana. 1999. 189 f. Tese (Doutorado em Engenharia Civil) - Escola Politécnica da Universidade de São Paulo, São Paulo, 1999.

TAKENAKA, E. M. M. Políticas Públicas de Gerenciamento Integrado de Resíduos Sólidos Urbanos no Município de Presidente Prudente-SP. Presidente Prudente: FCT, UNESP, 2008, 232f. Tese (Doutorado) - Faculdade de Ciências e Tecnologia, Universidade Estadual Paulista, 2008.

TUNDISI, J.G.Ambiente, represas e barragens. Ciênc. Hoje, v.5, n.27, p.48-55, 1986. 